\title{
D0I: https://dx.doi.org/10.21879/faeeba2358-0194.2021.v30.n63.p30-45 \\ EDUCAÇÃO E FORMAÇÃO DE MULHERES: A REVISTA BEM-TE-VI NA PRIMEIRA METADE DO SÉCULO XX
}

\author{
Cristiane Pereira Peres* \\ Universidade Federal da Grande Dourados \\ https://orcid.org/0000-0002-5906-2834 \\ Alessandra Cristina Furtado** \\ Universidade Federal da Grande Dourados \\ https://orcid.org/0000-0002-6084-2299
}

\section{RESUMO}

Este artigo analisa como a educação e a formação de mulheres foram pensadas em espaços para além da fé protestante, na primeira metade do século XX. Para isso, toma-se como fonte principal de pesquisa um impresso periódico protestante, revista Bem-te-vi, que circulou nesse período na Escola da Missão (Escola Primária General Rondon) na Reserva Indígena de Dourados (RID). Além do periódico, também se analisa o jornal $O$ Puritano. As fontes mobilizadas foram analisadas a partir dos pressupostos teóricos da História Cultural. 0 estudo dos conteúdos editados nas páginas da revista Bem-te-vi na primeira metade do século XX e direcionados à educação e à formação das mulheres, usados na Escola da Missão na RID, buscavam incutir padrões do universo feminino às meninas e mulheres indígenas, construídos e legitimados pela cultura ocidental. Constata-se, assim, que a Revista em análise, no período, constitui-se em um veículo de divulgação dos valores protestantes metodistas que ultrapassa os espaços de fé do protestantismo, que, juntamente com o jornal $O$ Puritano, permitiu compreender e refletir sobre os processos educativos e formativos de mulheres em espaços indígenas.

Palavras-chave: imprenso metodista; conteúdos de educação feminina; mulheres indígenas.

\section{ABSTRACT}

\section{EDUCATION AND TRAINING FOR WOMEN: THE BEM-TE-VI MAGAZINE IN THE FIRST HALF OF THE 20TH CENTURY}

This article analyzes how the education and training of women were conceived in spaces beyond the Protestant faith, in the first half of the 20th century. For this,

* Doutoranda em Educação pela Universidade Federal da Grande Dourados (UFGD). Dourados, Mato Grosso do Sul. Brasil. E-mail: cristiapereira@hotmail.com

** Pós-Doutorado em Educação pela Universidade de São Paulo (USP). Doutorado em Educação pela Universidade de São Paulo (USP). Professora Associada III da Faculdade de Educação da Universidade Federal da Grande Dourados (FAED/UFGD). Dourados, Mato Grosso do Sul. Brasil. E-mail: alessandrafurtado@ufgd.edu.br 
the main source of research is a Protestant periodical printed in the magazine Bem-te-vi, which circulated during this period at the Mission School (Escola Geral Geral General Rondon) in the Indigenous Reserve of Dourados (RID). In addition to the periodical, the newspaper $O$ Puritano is also analyzed. The sources mobilized were analyzed from the theoretical assumptions of Cultural History. The study of the contents edited on the pages of Bem-te-vi magazine in the first half of the 20th century and aimed at the education and training of women, used at the School of Mission in the RID, sought to instill patterns of the feminine universe in indigenous girls and women, built and legitimized by Western culture. It can be seen, therefore, that the journal under analysis, in the period, constitutes a vehicle for the dissemination of Protestant Methodist values that surpasses the spaces of faith of Protestantism, which together with the newspaper $O$ Puritano, allowed to understand and reflect on the educational and training processes of women in indigenous spaces.

Keywords: methodist press; female education content; indigenous women.

\section{RESUMEN}

\section{EDUCACIÓN Y FORMACIÓN DE MUJERES: LA REVISTA BEM-TE-VI EN LA PRIMERA MITAD DEL SIGLO XX}

Este artículo analiza cómo se pensó la educación y formación de la mujer en espacios más allá de la fe protestante, en la primera mitad del siglo XX. Para ello, la principal fuente de investigación es un periódico protestante impreso en la revista Bem-te-vi, que circuló durante este período en la Escuela Misionera (Escola Geral Geral General Rondon) en la Reserva Indígena de Dourados (RID). Además del periódico, también se analiza el diario $O$ Puritano. Las fuentes movilizadas fueron analizadas a partir de los supuestos teóricos de la Historia Cultural. El estudio de los contenidos editados en las páginas de la revista Bemte-vi en la primera mitad del siglo XX y orientados a la educación y formación de la mujer, utilizados en la Escuela de Misión del RID, buscó inculcar patrones de la universo femenino en niñas y mujeres indígenas, construido y legitimado por la cultura occidental. Parece, por tanto, que la revista bajo análisis, en el período, constituye un vehículo de difusión de los valores metodistas protestantes que supera los espacios de fe del protestantismo, que junto con el diario $O$ Puritano, permitió comprender y reflexionar sobre los procesos educativos y de formación de las mujeres en los espacios indígenas.

Palabras clave: prensa metodista; contenido de educación femenina; mujeres indígenas. 


\section{Introdução}

Com a renovação da pesquisa em História da Educação no Brasil, nas últimas décadas, novos objetos e temas, assim como novos problemas e procedimentos de análise, integraram-se à investigação, favorecendo outros caminhos para o seu estudo. Entre esses novos domínios está a imprensa periódica para a realização de estudos e pesquisas com a escrita da História da Educação. 0 interesse por essa imprensa com caráter historiográfico sobre a educação brasileira remete ao final da década de 1980, ${ }^{1}$ intensificando-se a partir da década de $1990,{ }^{2}$ quando esses trabalhos se tornaram mais recorrentes na produção acadêmica.

A revolução historiográfica estabelecida pela Escola dos Annales e da Nova História culminou, dentre outros fatores, na expansão documental como fonte de investigação, e o uso da imprensa começou a ser disseminado nos diversos campos de pesquisa, principalmente nos inseridos na perspectiva da Nova História Cultural, proporcionando o distanciamento "[...] de um tempo em que a imprensa era considerada como fonte suspeita, a ser usada com cautela, pois apresentava problemas de credibilidade" (CRUZ; PEIXOTO, 2007, p. 254).

No campo da pesquisa em História da Educação, o impresso periódico vem sendo tomado tanto como fonte ou como objeto, quanto como fonte e objeto. No entendimento de Oliveira (2003, p. 79), é preciso reconhecer a dupla possibilidade de utilização desses impressos periódicos pela história da educação: como fonte e como objeto, "Partindo das possibilidades apresentadas pela análise de periódicos para a escrita da história da educação, naquilo que diz respeito especificamente à conformação das práticas escolares, bem como os objetivos desse trabalho."

1 A esse respeito, pode-se consultar a pesquisa de Catani (1988).

2 A esse respeito, pode-se consultar as produções a partir da década de 1990, como Bastos (1994), Catani $(1996,2003)$, Catani e Sousa (1999), Oliveira (2003), Pinto (2001), Catani e Bastos (2002), Biccas (2008), Zanlorenzi (2010), Silva (2012), Panizzolo (2014).
No caso, os impressos periódicos podem ser considerados como fontes para compreender o campo educacional, uma vez que permite ao "[...] pesquisador estudar o pensamento pedagógico de um determinado setor ou grupo social, a partir da análise do discurso veiculado e a ressonância dos temas debatidos, dentro e fora do universo escolar" (CATANI; BASTOS, 2002, p. 5). Além disso, possibilita a percepção da realidade e de metodologias utilizadas em outros momentos, retratando a trajetória da educação em diversos aspectos, permitindo, assim, apreender reflexões muito próximas ao acontecimento.

É certo que os impressos periódicos fazem circular em seus conteúdos "[...] o trabalho pedagógico, o aperfeiçoamento das práticas docentes, o ensino específico das disciplinas, a organização dos sistemas, as reivindicações da categoria do magistério e outros temas", conforme assinalam Catani e Bastos (2002, p. 7). Além disso, possibilitam fazer a relação entre concepções pedagógicas e estratégias editoriais, destacando a produção, a circulação e o seu uso. Assim, esses impressos permitem compreender as diversas dimensões do campo pedagógico e entrever o que determinados grupos e atores pensavam em um determinado período. Do mesmo modo, proporcionam a compreensão das formas de funcionamento da educação, uma vez que fazem circular elementos que facilitam entender o trabalho pedagógico, o ensino das disciplinas, a organização e outros fatores relacionados à educação, próprio do seu caráter "[...] fugaz e polêmico, a vontade de intervir na realidade que lhe conferem este estatuto único e insubstituível como fonte para o estudo histórico [...] da educação e da pedagogia" (NÓVOA, 2002, p. 31).

Em outra publicação, Nóvoa (1993) assinala que a imprensa é, talvez, o melhor meio para compreender as dificuldades de articulação entre a teoria e a prática, ou seja, o senso comum, que perpassa as páginas dos jornais e das revistas. Isso porque esclarece uma das qualidades 
de um discurso educacional que se constrói a partir dos diversos autores em presença.

É dentro do quadro anteriormente delineado dos impressos periódicos que este artigo emerge com o objetivo de analisar como a educação e a formação de mulheres foram pensadas em espaços para além da fé protestante, na primeira metade do século XX, tomando como fonte principal de pesquisa um impresso periódico protestante, a revista Bem-te-vi, que circulou também nesse período na Escola da Missão (Escola Primária General Rondon) na Reserva Indígena de Dourados (RID). Para tanto, o problema visa contribuir para a compreensão da seguinte questão: como a revista Bem-te-vi tratou em suas páginas os conteúdos sobre a educação e a formação de mulheres, sendo os referidos conteúdos inseridos em espaços para além da fé protestante, e ainda serviu para reforçar o ideário protestante, na primeira metade do século XX.

Dito isso, este estudo partiu da hipótese de que os protestantes recorreram à imprensa para a propagação de seu credo religioso, com a publicação da revista Bem-te-vi, no início da década de 1920, em um período marcado pelo movimento de restauração católica, em que a Igreja Católica buscava o restabelecimento de seus privilégios, que perdeu com a Proclamação da República no Brasil, com a separação entre a Igreja e o Estado. Com isso, puderam tratar, inclusive, nas páginas dessa Revista questões relacionadas a educação e a formação de mulheres, podendo, assim, inserir esses conteúdos em espaços para além da fé protestante, na primeira metade do século XX.

A delimitação do recorte temporal deste artigo justifica-se em razão de a revista Bem-te-vi, tomada como fonte principal do estudo, ter sido escrita a partir de 1922 e inserida na RID pelos missionários protestantes metodistas após o ano de 1929 , período em que se instalaram na Reserva. $^{3}$

3 Nesse período, em Dourados, os católicos já haviam se instalado, com a construção da primeira Capela Nossa Senhora Imaculada Conceição, no ano de 1925; posteriormente, em 1935, foi criada a Paróquia Nossa Senhora Imaculada
Em se tratando do campo de pesquisa da História da Educação, eleger um impresso de natureza religiosa e pedagógica como fonte de pesquisa tornou-se possível com as contribuições da Nova História Cultural, a partir da década de 1990, que reconheceu a necessidade de “[...] investigação da composição social e da vida cotidiana de operários, criados, mulheres, grupos étnicos e congêneres" (HUNT, 1992, p. 2). Esse é, então, o período em que a história compreende "Novos objetos, problemas e sentidos se ensaiam, marcados por um ecletismo teórico e um grande apelo em termos de fascínio temático" (PESAVENTO, 1995, p. 9-10).

No Brasil, as inovações trazidas pela Nova História Cultural, difundidas especialmente por meio dos trabalhos do historiador francês Roger Chartier, “[...] vem impactando e marcando a produção historiográfica contemporânea e de modo particular a história da educação" (BICCAS, 2008, p. 27), no sentido de apresentar indicações e possibilidades sobre como abordar impressos periódicos em estudos historiográficos.

Para desenvolver este artigo, além da revista Bem-te-vi, foi necessário recorrermos também ao jornal $O$ Puritano como fonte de pesquisa, que circulou com informações sobre o trabalho dos missionários protestantes e as atividades desenvolvidas com as mulheres indígenas na RID. É preciso compreender que os impressos periódicos como veículos de comunicação não são destituídos de ideologias políticas, sociais, religiosas, dentre outras, dos seus autores. Sendo assim, isto requer que os conteúdos da revista Bem-te-vi, tomada aqui como fonte principal de análise, e os conteúdos do jornal $O$ Puritano não sejam analisados como textos inocentes, conforme

Conceição, e em 1957, a Diocese de Dourados (LARA, 2017). Nesse contexto, pode-se afirmar que, na primeira metade do século XX, católicos e protestantes passaram a disputar espaços religiosos, mas também assistenciais, sociais, educacionais e políticos em Dourados, com a chegada dos protestantes no ano de 1929; a construção da Igreja Presbiteriana em 1936, da Escola Erasmo Braga em 1939 e, no ano de 1946, com a criação do Hospital Evangélico. Sobre esse tema, conferir ainda: Gonçalves (2011), Gressler e Swensson (1988), Marin (2011) e Moreira (1990). 
adverte Chartier (1990, p. 18), pois “[...] os documentos que descrevem ações simbólicas do passado não são textos inocentes e transparentes; foram escritos por autores com diferentes intenções e estratégias." Para tanto, foram analisadas, neste estudo, as edições da Revista de dezembro de 1933, março de 1942 e os números de janeiro a dezembro de 1939.

Utilizamos, ainda, as referências bibliográficas ligadas à história, à história da educação, à história das mulheres, à história da educação da mulher.

Sobre a organização deste estudo, o artigo divide-se em duas seções. Na primeira apresentamos a revista Bem-te-vi e o espaço de circulação deste impresso na RID, na primeira metade do século XX. Em seguida discutimos a educação e a formação de mulheres que circularam nas páginas da revista Bem-te-vi, com foco para uma proposta missionária para educar e formar mulheres indígenas.

\section{A circulação da revista Bem-Te- Vi para além dos espaços de fé protestante}

A revista Bem-te-vi, ainda com publicação atual, foi criada pelos protestantes metodistas no ano de 1922, para atender às crianças cristãs não indígenas, e constituiu-se em um dos primeiros periódicos voltados às crianças brasileiras. Até o ano de 1967, foi elaborado com o propósito de atender de forma especial às crianças cristãs, sem restrição à denominação religiosa. A partir deste período, sua publicação passou a ter "[...] um caráter instrumental voltado à catequese metodista, tendo sua destinação especificamente voltada para uso nas aulas das escolas dominicais" (PANIZZOLO, 2014, p. 274). Assim, após o ano de 1967, passou a ser utilizada especificamente nas escolas dominicais, no desenvolvimento das aulas da catequese metodista.

Não se pode deixar de mencionar aqui que a criação da revista Bem-te-vi ocorreu na dé- cada de 1920, conforme apontado em nossa hipótese neste artigo, em um período de movimento de restauração católica. Esse movimento buscava o restabelecimento de uma condição perdida pela Igreja Católica com a Proclamação da República em 1889, que estabeleceu legalmente a separação entre a Igreja e o Estado brasileiro e fez com que essa perdesse os seus privilégios, bem como sua condição de religião do Estado. Assim, com um Estado laico, a Igreja perderia também suas vantagens materiais com a secularização.

Com o intuito de recuperar e ampliar a sua presença junto ao poder, na condução da nação brasileira, durante a primeira República (18891930), a Igreja colocou em prática estratégias para unificar o episcopado brasileiro, entre elas a produção de documentos de doutrinação e o acionamento de parte da intelectualidade católica para difundir a Igreja país adentro. Tais estratégias se agruparam no emprego intenso da imprensa para espalhar o ideário católico, na hierarquia de poder (COELHO; ROMERA, 2016).

É justamente nesse contexto que a Igreja, buscando se rearticular institucionalmente e socialmente, reuniu e mobilizou forças em nome de uma unidade com respaldo do papado, conforme trata Azzi (1979). Nesse período, foi o cardeal dom Sebastião Leme que liderou e mobilizou intelectuais ${ }^{4}$ a se engajarem no movimento de restauração católica, por meio de suas intervenções, que se iniciaram em 1916, quando era arcebispo de Olinda e Recife, em Pernambuco, e se ampliaram a partir de 1921, quando se tornou arcebispo no Rio de Janeiro, onde exerceu liderança ativa nos propósitos da Igreja de restabelecer (elevar) sua posição (AZZI, 1979; COELHO; ROMERA, 2016).

4 Dom Leme conseguiu ser apoiado pelos representantes mais destacados do episcopado brasileiro, a saber: Dom Antônio dos Santos Cabral, Dom João Becker, Dom Duarte Leopoldo e Silva, Dom Joaquim Silvério de Souza e Dom Francisco de Aquino Correia. Também recebeu o apoio de grandes nomes da intelectualidade católica, como o padre jesuíta Leonel Franca. Entre os leigos destacaram-se na liderança do Centro Dom Vital, a ação prática-beligerante de Jackson de Figueiredo (IGLÉSIAS, 1971). 
Nesse cenário, "O 'Centro Dom Vital' e a 'Revista A Ordem' atuaram na mobilização da intelectualidade católica com ações direcionadas ao desafio de defender e propagar o ideário católico e de pensar a reação" (COELHO; ROMERA, 2016, p. 121). No início da década de 1920, a linha católica concentrou-se na defesa do catolicismo como religião universal e nas críticas ao protestantismo e ao espiritismo. De fato, o movimento de restauração católica realizou ações políticas objetivas para legitimar o status da Igreja como instituição corresponsável pelo governo do Brasil (AZZI, 1979; COELHO; ROMERA, 2016).

Provavelmente, diante desse cenário, podese dizer que a revista Bem-te-vi foi criada em 1922 pelos protestantes, para difusão do seu ideário religioso, mas não por acaso, e sim com o interesse de funcionar como um dispositivo que se contrapunha a esse movimento de restauração católica no período.

A revista Bem-te-vi, com publicação mensal, privilegiou, na primeira metade do século $\mathrm{XX}$, conteúdos que priorizaram a confissão protestante, as festas cristãs, a civilidade e a moralidade, a importância do trabalho, as receitas culinárias, os hinos e suas partituras e a educação feminina.

Para despertar o interesse das crianças para a leitura, a presença de animais nas histórias era marcante, como gatos, cachorros, cavalos, coelhos, elefantes e outros. É preciso reconhecer que a presença de animais nas histórias acabava por contribuir com a construção do cuidado, do respeito e do carinho das crianças para com os animais.

Essa Revista, mesmo tendo cunho pedagógico, e também moral, apresentou no período da sua criação abordagens inovadoras quanto à educação da criança, ao buscar atender às propostas das novas correntes educacionais que se desenvolviam no Brasil, como a da Escola Nova, assim como as das manifestações culturais organizadas pela Semana da Arte Moderna em 1922. Cumpre lembrarmos aqui que a Escola Nova foi uma crítica à escola tradicional, que possuía uma conduta voltada para a memorização dos saberes, ou seja, para a mecanização da repetição, permanecendo o aluno como ser passivo e reprodutor do professor que ensina e sem questionamentos. Desse modo, a Escola Nova introduziu uma nova maneira de fazer a educação, possibilitando uma maior participação do aluno, avaliando seu aprendizado de maneira qualitativa e sem tanta rigidez de memorização, posições necessárias devido às exigências vigentes no contexto social (VIDAL, 2000). Vidal (2000, p. 498) registra, ainda, que a Escola Nova "[...] pretendia a incorporação de toda a população infantil. Serviria de base à disseminação de valores e normas sociais em sintonia com os apelos da nova sociedade moderna, constituída a partir dos preceitos do trabalho produtivo e eficiente."

Nessa perspectiva, a Revista trazia em seus números mensais conteúdos de uma pedagogia tradicionalista, mas também de abordagens pedagógicas mais atualizadas. Assim, por meio da escrita, os impressos consolidam "[...] as sociabilidades e prescrevem os comportamentos, atravessam o foro privado e a praça pública, levam a crer, a fazer ou a imaginar [...]" (CHARTIER, 1990, p. 138).

Ao atentar-se às especificações dessa Revista, foi possível observarmos que os seus conteúdos estiveram relacionados ao projeto republicano da política educacional brasileira de formar uma sociedade civilizada, cívica e trabalhadora. Imperava nesse projeto uma construção nacional de pátria e família (CARVALHO, J., 2017).

A revista $B e m-t e-v i$, ainda na primeira metade do século $\mathrm{XX}$, não ficou restrita ao universo cristão, pois foi inserida nos espaços em que os missionários protestantes instalaram as missões, como na RID. É preciso explicar que essa Reserva foi criada no ano de 1917, sendo povoada pelas etnias Kaiowá, Guarani e Terena. E no ano de 1929 foi instalada na RID a Missão Evangélica Caiuá (MEC), que passou a realizar “[...] os serviços agrícolas, assistên- 
cia médica dentária, e ensino primário e da Palavra de Deus" (O PURITANO, 1929b, p. 7). Tais serviços foram viabilizados com a construção, durante a primeira metade do século $\mathrm{XX}$, da escola primária e escola dominical, do hospital, do orfanato e da igreja, objetivando civilizar, escolarizar e evangelizar os indígenas.

Os textos que circulavam pela revista $\mathrm{Bem}$ te-vi voltam-se a um leitor infantil. Desse modo, os textos utilizam expressões mais simples, com conteúdos direcionados aos supostos interesses das crianças e adotam personagens associados ao universo infantil e à imaginação das crianças, como fadas, príncipes e serviçais transcritos e interpretados de acordo com os princípios morais protestantes, visando a modelar o comportamento dos pequenos leitores (PANIZZOLO, 2014).

Assim, a primeira equipe que fundou a MEC foi organizada para atender aos indígenas na educação, saúde, trabalho e religião, sendo composta pelo reverendo presbiteriano Alberto Sidney Maxwell e por sua esposa Mabel Davis Maxwell, pelo médico metodista Nelson de Araújo, o professor e dentista presbiteriano Esthon Marques e o agrônomo presbiteriano João José da Silva, em companhia da sua esposa Guilhermina Alves da Silva (professora) e de seu filho Erasmo (O PURITANO, 1929a).

Nesse contexto, "[...] as fronteiras são, frequentemente, palcos de encontros culturais" (BURKE, 2008, p. 154). Na RID, metodistas, presbiterianos, indígenas com culturas e línguas diferentes passaram a conviver e tiveram de construir novas maneiras para se relacionarem no espaço multiétnico formado a partir das frentes de colonização e expansão religiosa protestantes no sul de Mato Grosso na primeira metade do século XX.

Nesses espaços, os protestantes, por meio da evangelização e da escolarização, inseriram novos conhecimentos com o objetivo de construir entre os indígenas novos valores, comportamentos, crenças, hábitos quanto ao trabalho e à higiene, e novas relações sociais e familiares. Para os missionários, a MEC estava "[...] entre o índio e a civilização como o desvio do mal [...]" (O PURITANO, 1952, p. 4).

Os indígenas passaram a receber as primeiras instruções religiosas e escolares assim que os missionários se instalaram na Reserva, em uma construção improvisada próxima à sede do Posto Indígena Francisco Horta Barbosa, entre os anos de 1929 e 1930. Essa inserção efetivou-se por meio da alfabetização de adultos, dos encontros religiosos e das aulas na escola dominical.

Ao passo que foram se estruturando na RID, os missionários deixaram de ocupar os espaços improvisados, utilizados para os cultos, as aulas na escola primária e na escola dominical, e foram construindo a sede da MEC para ampliar o projeto missionário protestante e melhor acomodar os missionários e atender aos indígenas.

No ano de 1939, foi construído o templo-escola, um espaço destinado à igreja e à escola, em que eram realizadas as aulas da escola primária, da escola dominical e da evangelização. Ampliar e melhor estruturar a Escola da Missão poderia atrair um maior número de matrículas, contribuindo com a efetivação do projeto protestante de civilizar, assimilar, escolarizar, evangelizar e integrar os indígenas à sociedade não indígena. Para esse alcance, contou com a educação e a formação de mulheres contidas na revista Bem-te-vi.

\section{A revista Bem-Te-Vi usada como proposta para educar e formar mulheres indígenas na RID}

Os conteúdos de educação feminina que compõem a revista Bem-te-vi passaram a ser utilizados pelos professores na escolarização desenvolvida na Escola da Missão, assim que o ensino escolar passou a acontecer na MEC, embora os referidos conteúdos não tivessem sido elaborados para atender às crianças indígenas.

Diante da ausência de material didático, os professores recorreram aos impressos protes- 
tantes e à cartilha de alfabetização do período (LOURENÇO FILHO, 1943) para alfabetizar as crianças e os adultos indígenas (CARVALHO, R., 2004).

O manuseio do material pelas crianças e adultos aproximava-os da cultura não indígena, objetivo do protejo de evangelização e escolarização da MEC. Nesse contexto, ao folhear as páginas da revista Bem-te-vi, os Kaiowá, Guarani e Terena recebiam informações e conteúdos referentes à educação feminina; o que contribuiria com a inserção de novos comportamentos civilizados entre as mulheres indígenas. Nessa perspectiva, entendemos que o processo civilizador se estabelece "[...] numa mudança na conduta e nos sentimentos humanos, através da implantação de regras comportamentais" (ELIAS, 2011, p. 193-194).

Cabe apresentar que a educação da criança foi priorizada pelos missionários após experiências de escolarização sem sucesso com os adultos, entre os anos de 1929 e 1930. Os protestantes perceberam que as crianças, por estarem no momento da construção de sua identidade e cultura, apresentavam menos resistência às novas informações passadas na Escola. Assim, com a frequência das crianças na Instituição, poder-se-ia aproximar os pais dos ensinamentos, mesmo que fosse com interesse ao que era oferecido aos alunos, como alimentação e presentes.

No contexto exposto, a infância representa “[...] mais do que um período definido biologi- camente, surge como categoria social ao longo das transformações que a sociedade vai sofrendo e se apresenta como referência histórica, cultural e social" (SARAT, 2009, p. 8), sendo construída a partir das vivências com as pessoas adultas e os ensinamentos que recebem.

Assim, aproximar as meninas e as mulheres indígenas da educação feminina não indígena colaborava com a formação de novos comportamentos, hábitos e valores entre os Kaiowá, os Guarani e os Terena, tendo como objetivo transformá-las em pessoas desenvolvidas, cívicas, cristãs, trabalhadoras e asseadas. Conforme apontou Pallares-Burke (1998), jornais e revistas disseminam e organizam informações, criam valores, atitudes e ideias que influenciam seus leitores. De tal modo, também para as mulheres, como sinalizou Luca (2012), as revistas, assim como outros periódicos, ensinam, aconselham, propõem formas de feminilidade consideradas como "normais", indicam condutas, o que fazer ou vestir, como agir ou se portar, do que gostar, o que é de bom ou mal tom em situações específicas de convívio do não indígena.

$\mathrm{Na}$ Revista, na primeira metade do século $\mathrm{XX}$, as mulheres aparecem nas imagens sempre realizando serviços manuais/domésticos, como cozinhar, organizar a casa, cuidar dos filhos, passando a mensagem de que a mulher é responsável pelo desenvolvimento dos serviços domésticos e pela paz e harmonia da família, como é possível observar nas Figuras 1, 2 e 3 a seguir.

Figura 1 - Participação da mulher mãe nas tarefas escolares dos filhos(as)

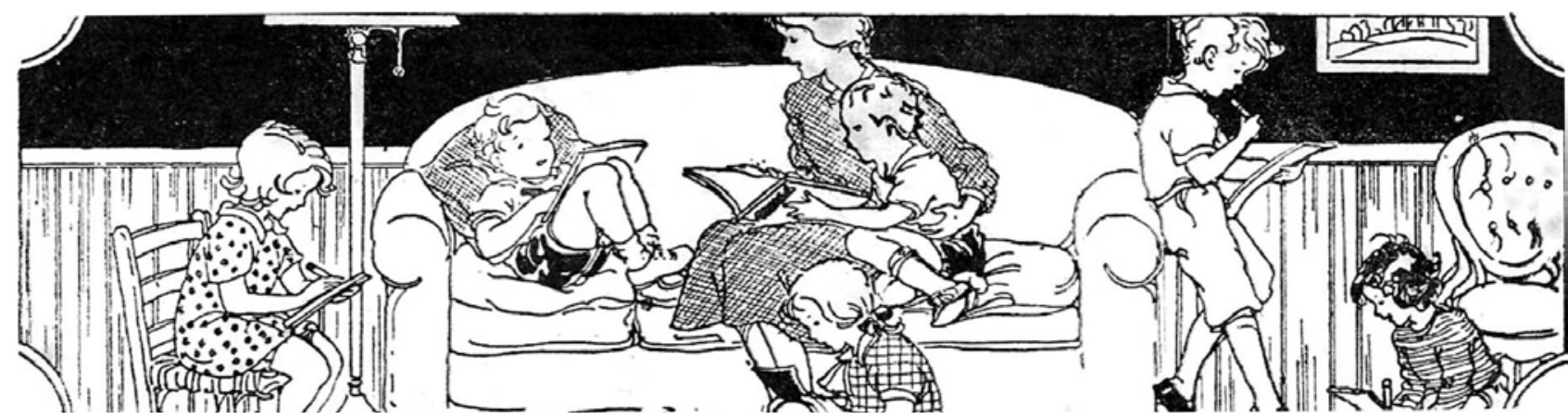

Fonte: Bem-te-vi (1942, p. 71). 
Figura 2 - A presença da mulher mãe em atividade de leitura e lazer com os filhos(as)

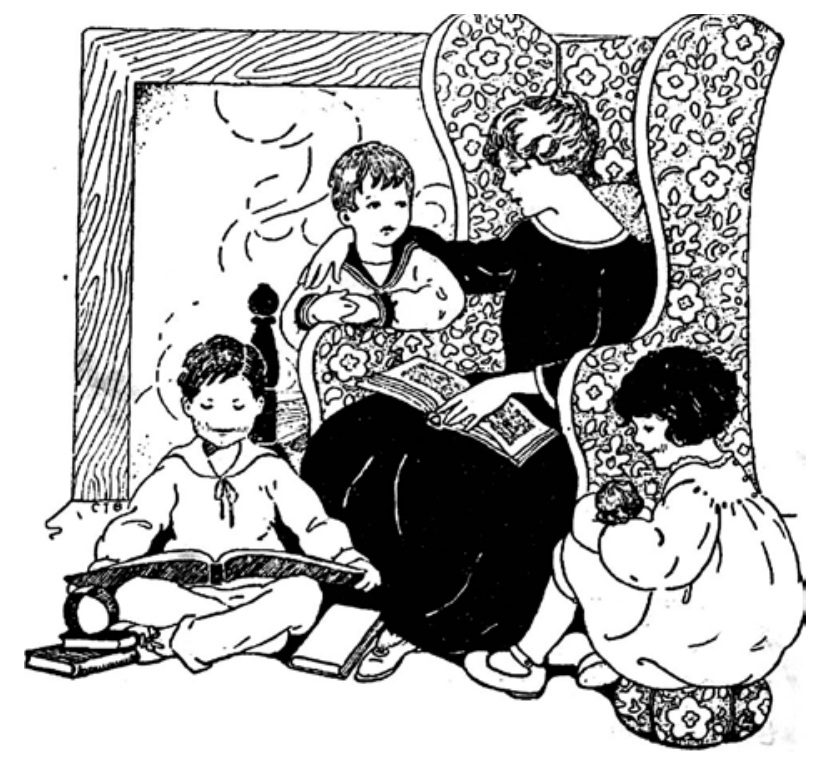

Fonte: Bem-te-vi (1933, p. 277).

Figura 3 - Participação da mulher mãe no banho do bebê com a ajuda da filha

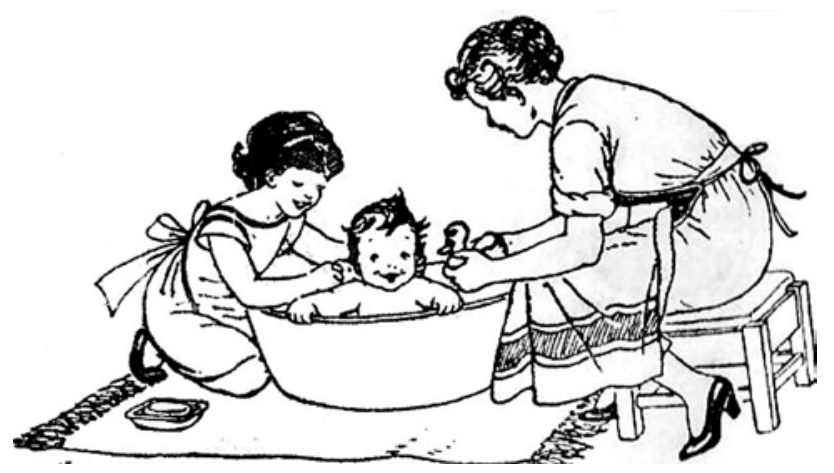

Fonte: Bem-te-vi (1939a, p. 2).

Dessas três figuras da Revista, depreendemos o modo de as mulheres ocuparem os seus espaços no cotidiano familiar e doméstico dentro dos seus lares. É importante destacarmos que essas mulheres são retratadas como pessoas dedicadas, amorosas, conselheiras, delicadas e religiosas, representando que cabe à mulher a organização e a realização dos trabalhos domésticos diários, como também o zelo pela educação dos filhos e pela felicidade da família. Assim, apoiava-se justamente no tripé composto pela supervalorização da mãe zelosa, da esposa amorosa e da dona de casa exemplar (BRUSCHINI; AMADO, 1988). Todavia, não podemos deixar de registrar aqui que na história das mulheres e, mais precisamente, na história da educação das mulheres, este tipo de educação lhes proporcionava uma formação para “[...] um sólido ambiente familiar, lar acolhedor, filhos educados e a esposa dedicada ao marido e sua companheira na vida social são considerados um verdadeiro tesouro [...]" (DEL PRIORE, 1997, p. 223), situação essa que perdurou por muitas décadas e marcou a geração, a formação e a educação de muitas mulheres.

Ainda não podemos deixar de dizer que a educação feminina, desse modo, acompanhava o movimento da lógica estabelecida para as mulheres que deveriam tornar-se boas esposas/mães, educadoras, formadoras de futuros cidadãos, conforme mencionado por Louro (2004, p. 446):

Ela precisaria ser, em primeiro lugar, a mãe virtuosa, o pilar de sustentação do lar, a educação das gerações do futuro. A educação da mulher seria feita, portanto, para além dela, já que a sua justificativa não se encontrava em seus próprios anseios ou necessidades, mas em sua função social de educadora dos filhos.

Aliás, foi justamente por essa porta que, nesse período da República, nas primeiras décadas do século XX, de construção de uma nação com civilidade, cívica e cristã, a mulher simbolizava a humanidade (CARVALHO, J., 2017).

Certamente essas três imagens de mulheres apresentadas às meninas e mulheres indígenas buscaram construir novos comportamentos e relações com a família, a individualidade e a casa, que não pertenciam às culturas indígenas e à realidade social e econômica. Como lembra Chartier (1990, p. 17), pode-se dizer que as imagens que circularam nas páginas da revista Bem-te-vi, "[...] não são de forma alguma discursos neutros: produzem estratégias e práticas", pois é certo que os cuidados com os filhos, a relação com a casa e a família nas comunidades indígenas ocorrem de modo diferente da realidade dos não indígenas. Contudo, nas relações estabelecidas pelos missionários protestantes na Escola da Missão, as culturas, as crenças e os saberes tradicionais indígenas não foram (re) 
conhecidos nem respeitados. Desse modo, buscou-se romper com as manifestações culturais indígenas e com seus saberes para inculcar a cultura ocidental caracterizada como civilizada. Percebemos, assim, que a revista Bem-te-vi, com os seus discursos postos em circulação na MEC, não apresenta um discurso neutro, pois, de acordo com Chartier (1990, p. 17), "[...] tendem a autoridade à custa de outras, por elas menosprezadas". Desse modo, acaba tendo como estratégia legitimar às mulheres indígenas uma educação e formação no modelo da cultura ocidental.

Outro indício da revista Bem-te-vi na formação e na educação das mulheres também se fez presente nas capas desse impresso. A capa referente à edição da Revista de maio de 1939, por exemplo, no mês em que é comemorado o dia das mães, reforça a imagem da mulher e mãe dedicada ao lar, carinhosa, presente e habilidosa nos trabalhos manuais, como a tecelagem. Ao mesmo tempo que tece, a mãe cuida do filho, como podemos observar na Figura 4 a seguir.

Figura 4 - Capa da Revista da edição de maio de 1939

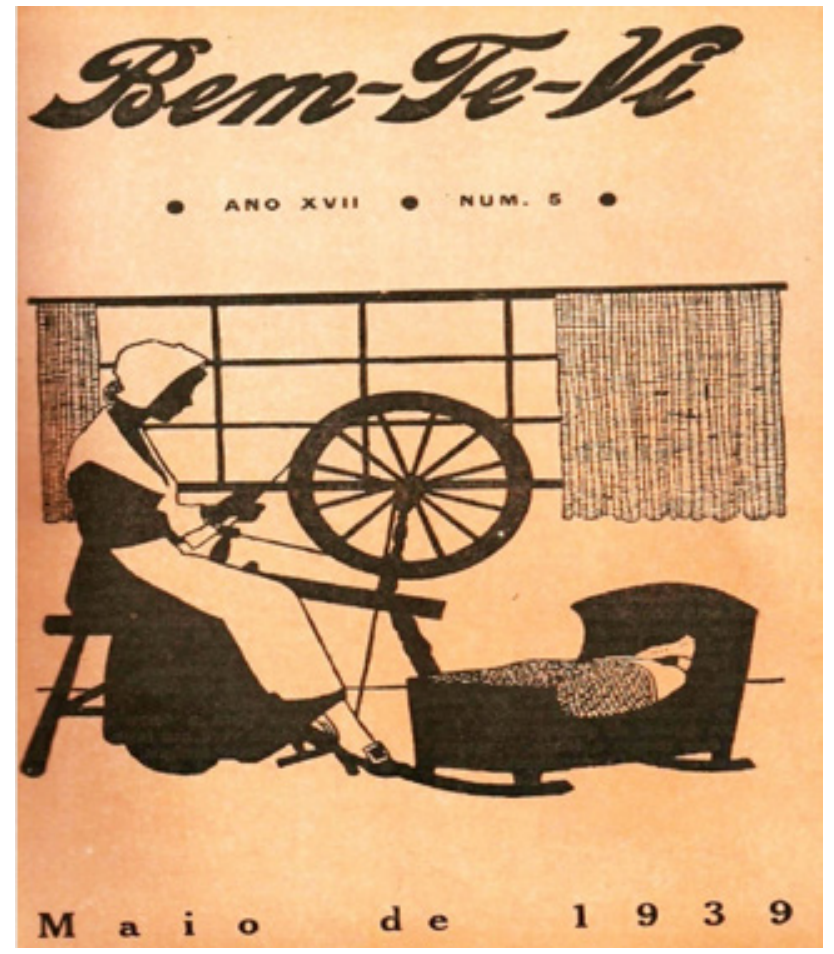

Fonte: Bem-te-vi (1939b).

Percebemos que essa capa busca evidenciar a valorização e os ensinamentos dos trabalhos manuais pertencentes à cultura ocidental, passados pela Revista. Assim, pudemos verificar que, na RID, as meninas e as mulheres indígenas receberam aulas de costura e tecelagem, que também eram valorizadas na revista Bem-te-vi. Nessas circunstâncias, cumpre inferirmos que as mulheres indígenas receberam aulas de costura e tecelagem com o objetivo de torná-las "civilizadas", capazes de conviverem na sociedade nacional e contribuírem com a formação da grande nação brasileira idealizada pelos republicanos. "Além da escola diária para as crianças, há uma escola noturna para adultos, bem como aulas de costura para as mulheres" (O PURITANO, 1949, p. 1). "Há uma modesta Escola Vocacional em formação, já com curso de Tecelagem. 16 teares civilizados lá estão, modestos, mas com um programa bom pela frente" (BRASIL PRESBITERIANO, 1962, p. 6). ${ }^{5}$

Embora, neste artigo, as fotografias não sejam o foco de nossas análises, a foto reproduzida a seguir possibilita reforçar os conteúdos da revista Bem-te-vi sobre a existência de curso de tecelagem para as mulheres na RID. Conforme adverte Ginzburg (2007), o fio do relato nos ajuda a orientarmo-nos pelo labirinto da realidade com os rastros. Sendo assim, precisamos nos atentar para as minúcias e os detalhes dessa fotografia, pois ela nos apresenta esses rastros, ao evidenciar a presença de alunas indígenas do curso de tecelagem ministrado pela professora da MEC, Loide Bonfim Andrade. ${ }^{6}$

$5 \quad$ A partir de 1962 o jornal mudou de nome, de 0 Puritano para Brasil Presbiteriano, deixando de ser editado no Rio de Janeiro e passando a ser editado no Recife.

6 Nascida em 24/12/1917 em Caetité, na Bahia, filha de Alexandre Soares Bonfim e Rita Andrade Angélica Teixeira, Loide concluiu o curso ginasial no Colégio Anglo-Americano em São Paulo, onde aprendeu fluentemente o inglês; foi estudar Pedagogia da Educação Religiosa no Instituto Bíblico Eduardo Lane (IBEL) em Patrocínio/MG. Passou a se interessar pelos trabalhos desenvolvidos com os indígenas e, em 1938, veio para Dourados/MT trabalhar como professora missionária na Missão Evangélica Caiuá (MEC). Em 1942, casou-se com o Reverendo Orlando Andrade e, em 1943, juntos assumiram a direção da MEC em substituição ao Reverendo Albert Maxwel, fundador da Missão, que por problemas de saúde precisou retornar para os Estados Unidos. 
Figura 5 - Professora e alunas indígenas do curso de tecelagem

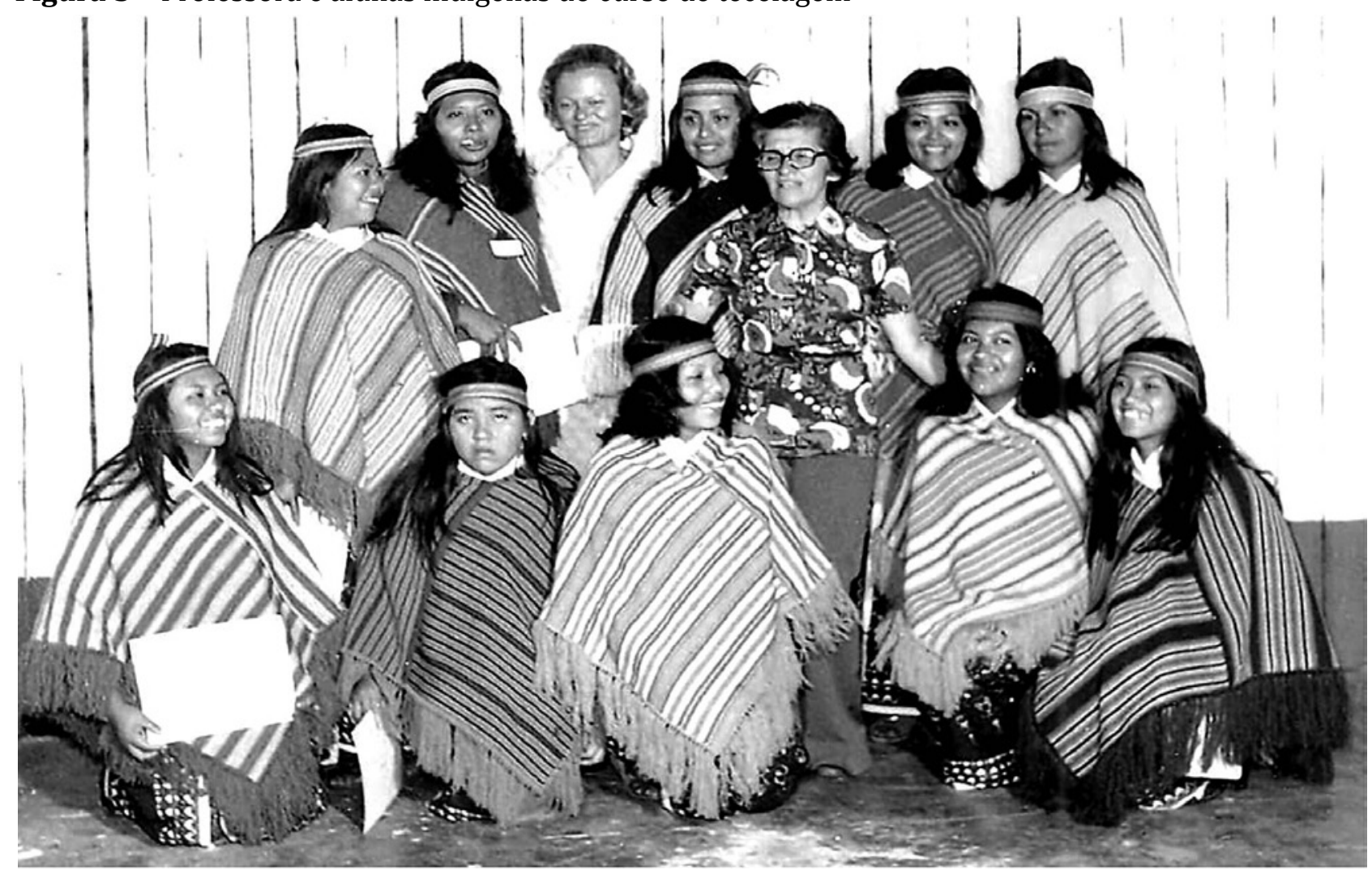

Fonte: Arquivo pessoal da família Bonfim Andrade.

Não é novidade que a fotografia permite entrever talvez até mesmo um momento de celebração de formatura das alunas indígenas no curso de tecelagem, uma vez que apresenta as alunas juntamente com a professora. As indígenas usam poncho e uma faixa do mesmo tecido do poncho na cabeça, e algumas delas seguram um papel de cor branca nas mãos, que, provavelmente, deve ser o certificado de conclusão do curso. Embora com algumas delas o papel esteja mais evidente, com outras alunas este papel aparece mais escondido. A professora Loide Bonfim Andrade aparece na fotografia, da direita para a esquerda, como a terceira mulher, em pé, vestida com uma blusa com estampas e com uma calça de cor escura; usa óculos e está rodeada pelas alunas, e também por uma outra mulher não-indígena, mais ao fundo, que não foi possível identificar.

Mesmo que as aulas de tecelagem tivessem objetivo de assimilar, civilizar e integrar as mulheres indígenas à sociedade nacional, “Dia virá quando em cada lar indígena haverá um desses teares, com índias trabalhando para prover a casa de recursos para a família" (BRASIL PRESBITERIANO, 1962, p. 6). A confecção e o uso de ponchos, por exemplo, poderiam ajudá-las a permanecer e conviver no cenário multiétnico que se configurava na RID e enfrentar os dias frios.

Aqui ainda cumpre inferirmos que a revista Bem-te-vi, com os seus conteúdos, e os conteúdos do jornal $O$ Puritano, e a fotografia que retrata a formatura do curso de tecelagem, acabavam também buscando a educação e a formação de mulheres para além de donas de casa, mulheres prendadas em seus afazeres domésticos: boas mães de família, mas também mulheres que fossem capazes, com os seus trabalhos manuais, de buscarem recursos para proverem a sua casa e família.

Importa destacarmos também que a circularidade de ideias e prescrições relacionadas aos trabalhos domésticos também circularam pelos conteúdos da revista Bem-te-Vi, uma vez que as meninas aparecem representadas nos conteúdos sempre realizando os trabalhos do- 
mésticos juntamente com as mães, o que deixa claro um processo educativo e de aprendizado da mulher para os trabalhos domésticos. Além disso, nesses conteúdos, essas meninas aparecem representadas sempre como educadas, comportadas, obedientes, o que permite compreender que estão sendo educadas e formadas para, quando estiverem adultas, serem mulheres responsáveis pelos filhos, pela família e cuidadosas com as suas casas, conforme esclarecem alguns estudos como os de Bruschini e Amado (1988), Del Priore (1997) e Louro (2002). Esses estudos apontam a formação das mulheres como donas de casa prendadas em seus afazeres domésticos, cuidadoras dos filhos, boas mães e esposas.

Ademais, há de se registrar aqui também que ensinar a cozinhar foi uma atividade doméstica bastante abordada pela Revista, pois em cada edição está presente uma receita voltada para as crianças, denominadas de "Petiscos para os Bem-te-vistas", como mostra a Figura 6 a seguir.

Figura 6 - Receita: petiscos para os bem-te-vistas

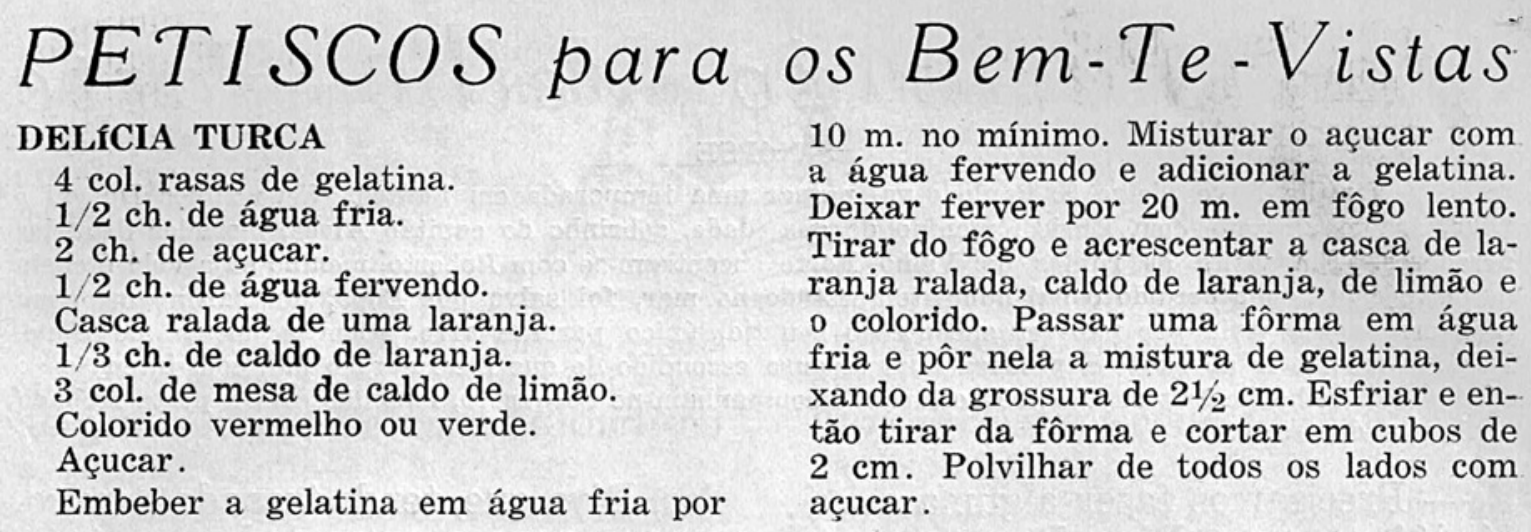

\section{DELICIA TURCA}

Fonte: Bem-te-vi (1939, p. 279).

Receitas como a da delícia turca, exposta na Figura 6, foi uma entre as receitas publicadas na seção denominada na revista como "Petiscos para os Bem-te-vistas", na qual sempre estavam presentes os mais diferentes tipos de receitas culinárias. 0 que possibilita perceber que nessa Revista os conteúdos com essas receitas buscavam aproximar as crianças do ato de cozinhar. Podemos dizer que servia como um instrumento de comunicação social que fazia parte da vida cotidiana das crianças e

Figura 7 - A participação da mulher mãe nas atividades de culinária com as filhas

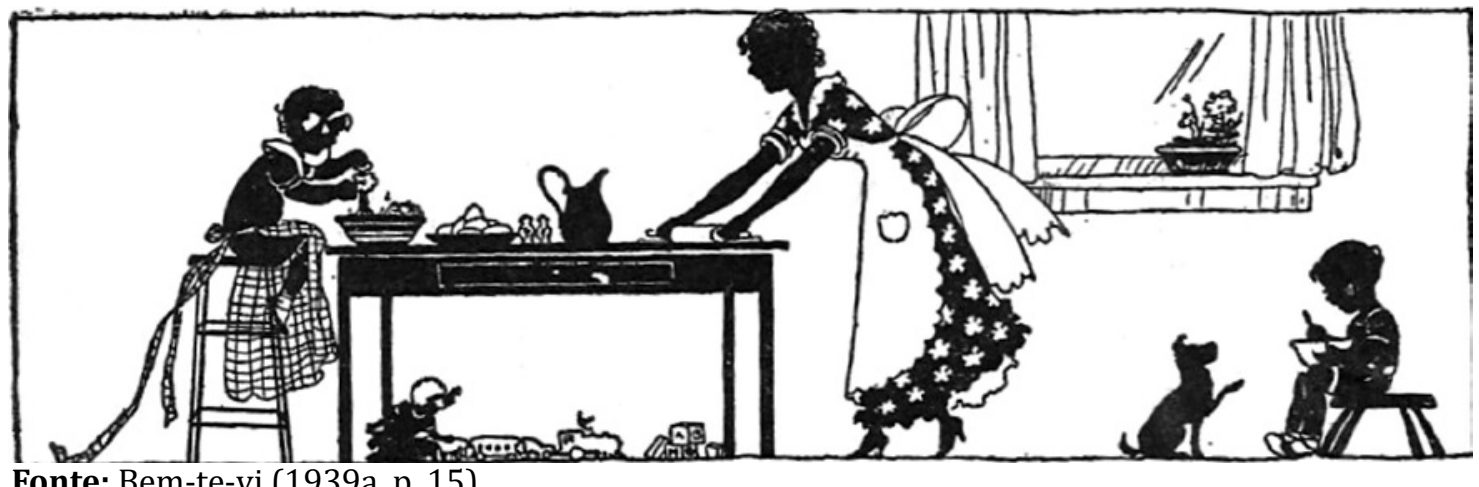

Fonte: Bem-te-vi (1939a, p. 15).

dos adultos. Desse modo, tornava-se também espaço de presença de educação, além de permanente ação educativa, conforme assinala Biccas (2008).

Todavia, as publicações destinadas ao trabalho doméstico quase sempre apresentavam a criança na companhia da mãe, pois a realização desse trabalho ia se construindo como natural e de responsabilidade centralizada nas mulheres, como podemos observar na Figura

7 a seguir. 
Ao analisar a imagem do trabalho doméstico na revista Bem-te-vi, podemos inferir que inculcar essa prática nas mulheres indígenas, em que a mãe pertencente à cultura ocidental aparece em seu cotidiano dentro de casa, mais especificamente em sua cozinha trabalhando junto com a filha em uma atividade de culinária, para os missionários era uma estratégia de torná-las cada vez mais próximas dos comportamentos e hábitos das mulheres ocidentais, elegidas como civilizadas. Essa aproximação possibilitava o aprendizado dos trabalhos domésticos: "A índia vai aprendendo a trabalhar e cuidar do filhinho - já lava roupa e cuida das criações" (O PURITANO, 1944, p. 7).

Como as mulheres indígenas realizavam os trabalhos de modo diferente das mulheres não indígenas, para os missionários protestantes, elas não sabiam realizá-los. Por isso, aos olhos dos religiosos não se dedicavam o esperado para o lar e a família, pois apresentavam, a partir das diferenças culturais, formas e tempos distintos para realizar os trabalhos na comunidade indígena, sendo consideradas como desorganizadas, sujas e preguiçosas. Conforme postula Chartier (1991, p. 177), não há “[...] prática ou estrutura que não seja produzida pelas representações, contraditórias e em confronto, pelas quais os indivíduos e os grupos dão sentido ao mundo que é deles." Era necessário, então, para os não indígenas, civilizá-las, para tirá-las da incivilidade e da incultura, sendo a educação feminina uma alternativa para efetivar o projeto civilizador protestante.

Os conteúdos editados nas páginas da revista Bem-te-vi, na primeira metade do século $\mathrm{XX}$, direcionados à educação e à formação das mulheres, podem ser caracterizados também como veículos de divulgação dos protestantes os quais vão além dos espaços de fé do protestantismo, como foi o caso ocorrido na Escola da Missão, nesse período, buscando, por meio dos conteúdos desse impresso, a educação e a formação das meninas e mulheres indígenas.

Podemos afirmar, de acordo com Chartier (1990), que a representação criada e difundida nas páginas da revista Bem-te-vi sobre educação e formação das mulheres na primeira metade do século XX acabava por funcionar como uma força reguladora da vida coletiva imposta por aqueles que detêm o poder de classificar, legitimando valores. Aqui vale lembrarmos que mesmo a Revista não se direcionando diretamente às meninas e mulheres indígenas, 0 seu uso na MEC também buscou regular a vida coletiva dessas mulheres, procurando legitimar valores não pertencentes às culturas indígenas. Particularmente, por meio dos conteúdos veiculados nas páginas da revista Bem-te-vi, os seus usos em relação à educação e à formação das mulheres na MEC buscavam incutir padrões do universo feminino às meninas e mulheres indígenas, construídos e legitimados pela cultura ocidental.

\section{Considerações Finais}

Um artigo desta natureza permitiu-nos compreender e refletir sobre os processos educativos e formativos de mulheres, a fim de analisar a forma como a educação e a formação de mulheres foram pensadas em espaços para além da fé protestante, na primeira metade do século XX, tomando como fonte principal de pesquisa um impresso periódico protestante, a revista Bem-te-vi, que circulou também nesse período na Escola da Missão (Escola Primária General Rondon) na RID. Assim, podemos dizer que os impressos periódicos, enquanto fontes privilegiadas para pesquisa, constituem-se como indícios, pistas e vestígios do discurso que se constrói a partir dos diversos autores que escrevem nesses impressos postos em circulação no cotidiano, em espaços como igrejas, escolas, entre outros.

Nesse contexto, podemos afirmar que a revista Bem-te-vi, tomada como fonte principal da pesquisa, juntamente com o jornal $O$ Puritano, ambos de origem protestante, constituíram-se como fontes importantes para a compreensão da formação e da educação das meninas e mulheres que estiveram presentes, na primeira 
metade do século XX, na RID. No caso da revista Bem-te-vi, à medida que seus conteúdos acerca da educação e da formação de mulheres foram abordados e direcionados às crianças cristãs na primeira metade do século XX, objetivou-se a construção de novos hábitos e comportamentos entre as mulheres indígenas, por meio da substituição das culturas indígenas pela cultura ocidental. Isso porque a inserção de novos conhecimentos e práticas domésticas buscou direcionar as mulheres indígenas para os serviços domésticos e para dedicação à família, tendo como modelo a cultura do não indígena. Assim, foram inseridos novos valores quanto ao cuidado com a casa e a forma pela qual deveriam se relacionar com a família, que também contribuíram com a permanência indígena e as relações mantidas no cenário multiétnico e multicultural que se formava na RID na primeira metade do século XX.

Os impressos, aqui, são analisados pela óptica das contribuições da Nova História Cultural, que possibilitou o alargamento das fontes e permitiu considerar documentos não oficiais como materiais possíveis de serem tomados como fonte de pesquisa, concedendo novos olhares e constituindo-se como novos campos da pesquisa em História da Educação. Assim, eleger como fonte de pesquisa a revista Bem-te-vi e o jornal $O$ Puritano possibilita-nos contribuir com a escrita da História da Educação a partir da seleção de novos objetos, novas fontes e abordagens teórico-metodológicas na compreensão de temáticas.

Por fim, esperamos que este artigo traga oportunidades para que outros pesquisadores acrescentem novos conhecimentos, dando continuidade a pesquisas que focalizam sob a perspectiva histórica da educação para os indígenas, pois não se esgotam aqui as possibilidades de investigações em torno da educação e da formação das mulheres indígenas, bem como a inclusão de novas fontes, novas abordagens e novas problemáticas em seu estudo. Para além desta perspectiva, esperamos também que este artigo abra novas possibilidades de pesquisas em torno da criação da revista Bem-te-vi, nos anos de 1920, e que seja analisado o seu papel, em contraposição ao movimento de restauração católica vigente no período, de difusão do ideário do protestantismo.

\section{REFERÊNCIAS}

AZZI, Riolando. 0 fortalecimento da restauração católica no Brasil (1930-1940). Síntese: Revista de Filosofia, v. 6, n. 17, p. 61-89, 1979. Disponível em: http://www.faje.edu.br/periodicos/index. php/Sintese/article/view/2291. Acesso em: 07 mar. 2021.

BASTOS, Maria Helena Câmara. 0 novo e o nacional em revista: a Revista do Ensino do Rio Grande do Sul (1939-1942). 1994. Tese (Doutorado em Educação) - Faculdade de Educação, Universidade de São Paulo (USP), São Paulo, 1994.

BEM-TE-VI. São Paulo, ano XI, n. 12, dez. 1933.

BEM-TE-VI. São Paulo, ano XVII, n. 1, jan. 1939a.

BEM-TE-VI. São Paulo, ano XVII, n. 5, maio 1939b.

BEM-TE-VI. São Paulo, ano XVII, n. 12, dez. 1939c.

BEM-TE-VI. São Paulo, ano XX, n. 3, mar. 1942.

BICCAS, Maurilane de Souza. 0 impresso como estratégia de formação - revista do ensino de Minas Gerais (1925-1940). Belo Horizonte: Argvmentvm, 2008.

BRASIL PRESBITERIANO. Recife, n. 5, maio 1962.

BRUSCHINI, Cristina; AMADO, Tina. Estudos sobre a mulher e a educação: algumas questões sobre o magistério. Cadernos de Pesquisa, São Paulo, n. 64, p. 4-13, 1988.

BURKE, Peter. 0 que é história cultural? Tradução Sergio Goes de Paula. 2. ed. Rio de Janeiro: Zahar, 2008.

CARVALHO, José Murilo de. A formação das almas: o imaginário da República no Brasil. 2. ed. São Paulo: Companhia das Letras, 2017.

CARVALHO, Raquel Alves de. Os missionários metodistas na região de Dourados e a educação indígena na Missão Evangélica Caiuá (19281944). 2004. 133 f. Dissertação (Mestrado em Educação) - Universidade Metodista de Piracicaba (UNIMEP), São Paulo, 2004.

CATANI, Denice Bárbara. A imprensa periódica educacional: as revistas de ensino e o estudo do 
campo educacional. Educação e Filosofia, n. 10, v. 20, p. 115-130, jul./dez. 1996.

CATANI, Denice Bárbara. Educadores à meia luz. 1988. Tese (Doutorado em Educação) Universidade de São Paulo (USP), São Paulo, 1988.

CATANI, Denice Bárbara. Educadores à meia-luz: um estudo sobre a Revista de Ensino da Associação Beneficente do Professorado Público de São Paulo. Bragança Paulista, SP: EDUSF, 2003.

CATANI, Denice Bárbara; BASTOS, Maria Helena Camara. Educação em revista: a imprensa periódica e a história da educação. São Paulo: Escrituras, 2002.

CATANI, Denice Bárbara; SOUSA, Cynthia Pereira. Imprensa periódica educacional paulista (1890-1996). São Paulo: Plêidade, 1999.

CHARTIER, Roger. História cultural: entre práticas e representações. Tradução Maria Manuela Galhardo. Lisboa: DIFEL; Rio de janeiro: Bertrand Brasil, 1990. (Coleção Memória e Sociedade)

CHARTIER, Roger. 0 mundo como representação. Estudos Avançados, São Paulo, v. 5, n. 11, p. 173191, jan./abr. 1991.

COELHO, Claudio Marcio; ROMERA, Edison. Reação católica e "questão religiosa" no Brasil Republicano. Estudos de Religião, v. 30, n. 3, p. 111-128, set./ dez. 2016.

CRUZ, Heloisa de Faria; PEIXOTO, Maria do Rosário da Cunha. Na oficina do historiador: conversas sobre história e imprensa. Projeto História, São Paulo, n. 35, p. 1-141, dez. 2007.

DEL PRIORE, Mary (org.). História das mulheres no Brasil. 2. ed. São Paulo: Contexto, 1997.

ELIAS, Norbert. 0 processo civilizador: uma história dos costumes. v. 1. 2. ed. Rio de Janeiro: Zahar, 2011.

GINZBURG, Carlo. 0 fio e os rastros: verdadeiro, falso, fictício. São Paulo: Companhia das Letras, 2007.

GONÇALVES, Carlos Barros. Até aos confins da terra: o movimento ecumênico protestante no Brasil e a evangelização dos povos indígenas. Dourados, MS: Ed. UFGD, 2011.

GRESSLER, Lori Alice; SWENSSON, Lauro Joppert. Aspectos históricos do povoamento e da colonização do Estado de Mato Grosso do Sul: destaque especial ao município de Dourados. Dourados, MS: L.A. Gressler, 1988.
HUNT, Lynn. Nova história cultural. São Paulo: Martins Fontes, 1992.

IGLÉSIAS, Francisco. História e ideologia. São Paulo: Perspectiva, 1971.

LARA, Camila de Brito Quadros. 0 patrimônio cultural religioso: história e memória da igreja Nossa Senhora Imaculada Conceição de Dourados/MS. 2017. 224 f. Dissertação (Mestrado em História) Universidade Federal da Grande Dourados (UFGD), Dourados, MS, 2017.

LOURENÇO FILHO, Manoel Bergström. Cartilha do povo - para ensinar a ler rapidamente. São Paulo: Melhoramentos, 1943.

LOURO, Guacira Lopes. Mulheres na sala de aula. In: PRIORI, Mary Del; BASSANEZI, Carla. História das mulheres no Brasil. 6. ed. São Paulo: Contexto, 2002. p. 441-481.

LOURO, Guacira. Mulheres na sala de aula. In: DEL PRIORE, Mary (org.). História das mulheres no Brasil. 7. ed. São Paulo: Contexto: UNESP, 2004. p. 443-481.

LUCA, Tania Regina de. Mulher em Revista. In: PINSKY, Carla Bassanezi; PEDRO, Maria Joana (org.). Nova história das mulheres. São Paulo: Contexto, 2012. p. 447- 468.

MARIN, Jérri Roberto. A Igreja Católica e o centenário da Diocese de Corumbá: história e imagens. Campo Grande, MS: UCDB, 2011.

MOREIRA, Regina Heloiza Targa. Memória fotográfica de Dourados. Campo Grande, MS: UFMS, 1990.

NÓVOA, Antônio. A imprensa de educação e ensino: repertório analítico (século XIX-XX). Lisboa: Instituto de Inovação Educacional, 1993.

NÓVOA, Antônio. A imprensa de educação e ensino. In: CATANI, Denice Bárbara; BASTOS, Maria Helena Câmara (org.). Educação em Revista: a imprensa periódica e a história da educação. São Paulo: Escrituras, 2002. p. 11-31.

O PURITANO. Rio de Janeiro, n. 1461, 06 abr. 1929a.

O PURITANO. Rio de Janeiro, n. 1465, 11 maio 1929b.

O PURITANO. Rio de Janeiro, n. 1819, jan. 1944.

O PURITANO. Rio de Janeiro, n. 1954, 25 out. 1949.

O PURITANO. Rio de Janeiro, n. 2018, 10 set. 1952.

OLIVEIRA, Marcus Aurélio Taborda de. Políticas públicas para a educação física escolar no Brasil durante a Ditadura Militar: uma só representação? 
Perspectiva, Florianópolis, v. 21, n. 1, p. 151-178, jan./jun. 2003.

PALLARES-BURKE, Maria Lúcia. A imprensa periódica como uma empresa educativa no século XIX. Caderno de Pesquisa, São Paulo, n. 104, p. 144- 161, 1998.

PANIZZOLO, Claudia. A revista Bem-te-vi e o projeto civilizatório metodista nas mãos da criança brasileira. Revista Brasileira de História da Educação, Maringá, PR, v. 14, n. 2, p. 271-293, maio/ ago. 2014.

PESAVENTO, Sandra Jatahy. Em busca de uma outra história: imaginando o imaginário. Revista Brasileira de História, São Paulo, v. 15, n. 29, p. 9-27, 1995.

PINTO, Adriana Aparecida. A Eschola Publica: um estudo da pedagogia paulista no século XIX (1893-1897). 2001. Dissertação (Mestrado em Educação) - Faculdade de Ciências e Filosofia, Universidade Estadual Paulista "Júlio de Mesquita Filho" (UNESP), Marília, SP, 2001.

SARAT, Magda. Infância e educação infantil: do renascimento à modernidade: In: SARAT, Magda.
Fundamentos filosóficos da educação infantil. Maringá, PR: Eduem, 2009. p. 9-21.

SILVA, Michele Juliana de Carli Anselmo da. A Revista Brasileira de Educação: apropriações do discurso acerca dos temas da infância e da história da infância - (1995 a 2010). 2012. 181 f. Dissertação (Mestrado em Educação) - Universidade Estadual de Maringá (UEM), Maringá, 2012. Disponível em: http://www.ppe.uem.br/dissertacoes/2012\%20 -\%20Michelle.pdf. Acesso em: 02 mar. 2021.

VIDAL, Diana Gonçalves. Escola nova e processo educativo. In: LOPES, Eliane Marta Teixeira; FARIA FILHO, Luciano Mendes de; VEIGA, Cynthia Greive (org.). 500 anos de educação no Brasil. Belo Horizonte: Autêntica, 2000. p. 497-517.

ZANLORENZI, Claudia Maria Petchak. História da Educação, fontes e a imprensa. Revista Histedbr On-line, v. 10, n. 40, p. 60-71, 2010. Disponível em: https://doi.org/10.20396/rho.v10i40.86398. Acesso em: 14 mar. 2021.

Recebido em: 25/03/2021

Aprovado em: 02/08/2021 